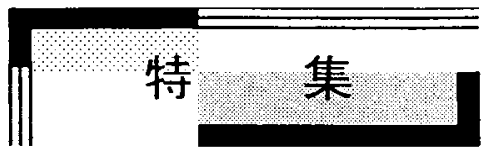

\title{
擋找槽の中の固液の流れ* （槽底からの固体粒子の浮遊と擋找羽根への粒子衝突）
}

\author{
Solid-liquid Mixing in a Stirred Vessel \\ (Particle Suspension from a Vessel Bottom and Particle Collision with Impeller Blades)

$\begin{array}{clc}\text { 三角 隆 太朕 } & \text { 仁志 和 彦** } & \text { 上ノ山 周** } \\ \text { MISUMI Ryuta } & \text { NISHI Kazuhiko } & \text { KAMINOYAMA Meguru }\end{array}$

\begin{abstract}
Solid-liquid mixing in a stirred vessel is widely used in chemical industrial processes, such as crystallization, leaching and chemical reaction by using solid catalysis. In these processes, control of sedimentation of particles on bottom is important to maximize efficiency of the chemical reaction and to prevent particle agglomeration. And particle collision with impeller blades often induces attrition and breakage of particles and erosion of the impeller blade. The mechanism of particle suspension from the vessel bottom and particle collision with impeller blade are not sufficiently understood, mainly because of the difficulties in experiments for characterizing detailed particle behavior.

In this study, the relation between particle rising behavior from a vessel bottom and liquid flow around bottom was clarified by using Computational Fluid Dynamics (CFD) coupled with the Lagrangian simulation of each particle motion. The results show that a common relation of four steps exists between particle rising behavior and fluid flow around bottom among different type of stirred vessels. That is (i) formation of stagnant region on bottom, (ii) sweeping of particles until the stagnant region, (iii) inducement of upward flow above the stagnant region, (iv) particles are caught up in the upward flow. And the particle collision behaviors with impeller blades, such as collision velocity and collision point distribution, were quantified. The results show that, on the front (loading) face of impeller blade, particle collision with large collision velocity concentrates along the blade edge. On the back face, particle collisions mainly occur around the center of blade face.
\end{abstract}

Keywords: Solid-liquid mixing, Stirred vessel, Impeller blade, CFD, Crystallization

\section{1. 緒 言}

固液摚拌操作は、晶析 - 沈殿、溶解、固体触媒 反応、吸着・イオン交換、スラリーの調製などの 化学工業プロセスにおいて頻繁に行われる操作 であり、その主な目的は液体中での固体粒子の分 散、ならびに固体粒子・液体間の物質移動を促進 させることにある。

一般的に、擋拌槽の中で摚拌翼の回転により形 成される旋回空間の体積は、槽全体の体積と比べ て数分の一から数十分の一と小さく、数十〜数百 $\mathrm{rpm}$ と比較的ゆっくりとした羽根の回転により 槽壁方向へ吐出された流れは規制の少ない空間 内で三次元的に複雑な挙動を示す。一方、擋拌装 置と同じく液体流を対象とした回転機械である ポンプでは、擋找翼と比較して羽根枚数が多く、 回転数も 10 倍程度大きい(数千 $\mathrm{rpm}$ )ことから、比 較的二次元性の強いフローパターンであり、擋拌 槽とポンプでは異なるとり扱いが必要となる。

汎用される 6 枚ディスクタービン翼を備えた 擋拌槽の中では、槽壁に沿って鉛直方向に設置さ

* 2014.11.21 受付

** 横浜国立大学大学院工学研究院 †240-8501 横浜市保土ケ谷区常盤台 79-5

TEL: (045)339-3995 FAX: (045)339-3995 E-mail: r-misumi@ynu.ac.jp 
れた 4 枚の邪魔板の効果により、撹拌翼の回転に より槽壁方向に吐出された流れは、槽壁に沿って 上方または下方への大きな循環流へと分岐され、 再び擋找翼近傍へ流入する輻流型 (放射流型) と 呼ばれるフローパターンが形成される。

この擋拌槽の中で固体粒子を取り扱う場合に は、おおきく次の 2 点が問題となるケースが多い。 (1) 固液擋拌操作の場合、固体粒子と溶液の接触 面積を最大とし、すべての固体粒子の表面積を化 学反応に寄与させるために、槽底で留まる粒子が なくなる最低の擋拌速度である完全浮遊化翼回 転数 $n_{\mathrm{JS}}$ が、操作条件選定の目安として用いられ る $[1,2]$ 。 $n_{\mathrm{JS}}$ は粒子の凝集抑制の観点からも重要 となる。ここで、 $n_{\mathrm{JS}}$ を決定づける槽底からの粒 子の浮遊メカニズムについては未解明の点が多 く、擋找翼の種類・フローパターンが異なる場合 に共通する流体力学的な因子について、明らかに する必要がある。(2) 一方、粒子の浮遊・分散性 を向上させるために擋拌速度を大きくすると、擋 拌羽根や邪魔板、槽壁などの固体面への固体粒子 の衝突が顕著となり、粒子の摩耗や破損が引き起 こされる。これは溶解プロセスでは反応を促進さ せる効果をもたらすが、固体触媒反応では高価な 触媒粒子の寿命を短くし、また晶析プロセスでは 結晶成長の阻害要因となり、さらには微小結晶の 発生による粒径分布の二峰化[3]につながる。スラ リーのように粒子の懸濁密度が大きくなると、擋 拌羽根の摩耗を誘起するケース $[4,5]$ もりり、多く の化学プロセスにおいて粒子衝突は制御すべき 現象となる。

擋挥槽の中の 3 次元的な流動状態を Computational Fluid Dynamics (CFD)により解析す る試みは、Hiraoka らの層流摚拌槽を対象とした 事例[6]や、上ノ山らの擬塑性流体を対象に回転座 標系を用いた試み[7,8]が始まりだと思われる。当 初、擋汼槽の中の混合効果を向上させるうえで不 可久な邪魔板と、回転する擋挥羽根との相対運動 を表現することが課題であったが、回転する擋挥 羽根を含む inner block と邪魔板と槽壁を含む outer block に分割する dynamic multi-block method [9]や定常流解析に対して回転座標系を改 良した multiple reference frames (MRF)モデル[10]、 非定常流解析に対応可能な sliding mesh model [11]などによる解析手法が利用されるようになっ た。
擋拌槽の中の固体粒子の挙動を CFD により再 現する試みは、過去 10 年の間に増えてきており、 個々の粒子の運動をラグランジアン的に解析す る事例も報告されている[12-14]。

本稿では、䀣濁粒子の沈降速度が大きい、いわ ゆる沈降性懸濁粒子液を対象として、著者らが粒 子運動のラグランジアン解析をもとに進めてい る研究例のうち、とくに(1) 槽底からの粒子浮遊 のメカニズム[15]と、(2) 擋找羽根や邪魔板、槽 壁への粒子の衝突現象 $[16,17]$ にいて、著者らの グループの研究事例を中心に概説する。

\section{2. 数值解析方法および解析条件}

Fig. 1 に解析領域概略を示す。対象とする擋拌 槽は内径 $T=0.1 \mathrm{~m}$ 、液深 $H=0.1 \mathrm{~m}$ の円筒平底槽 であり、槽壁には幅 $B=T / 10$ の邪魔板が 4 枚、 等間隔に設置されている。翼径が $d=0.05 \mathrm{~m}$ で 6 枚の平羽根が垂直に取り付けられた 6 枚垂直パ ドル翼を液深の 1 / 3 の位置に設置した。同翼は 固液摚拌操作で汎用される。

擋拌槽内の流動は連続の式、Navier-Stokes 方程 式を解き、乱流現象のモデル化には Large Eddy Simulation (LES)を用いた。粒子の運動は、個々の 粒子に対して運動方程式を解くラグランジアン 的手法により解析した。粒子間および粒子一固体 壁面間の相互作用は離散要素法 (Distinct Element Method: DEM)[18，19]を用い、これらの解析は汎 用熱流体解析ソフト RFLOW ((株)アールフロー 製)を用いて行った。

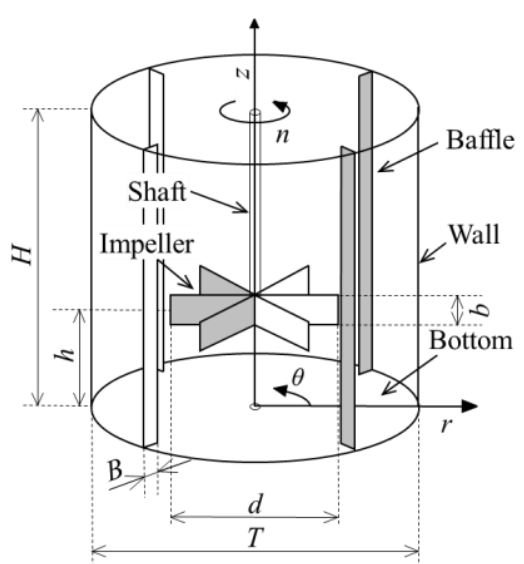

Fig. 1 Coordinate system and computational domain for a stirred vessel. 
固液摚拌操作で対象となる固体粒子を想定し て、粒子径を 100～200 $\mu \mathrm{m}$ 、粒子密度を 1000 $5000 \mathrm{~kg} / \mathrm{m}^{3}$ に変化させた。流体が静止し、粒子が 槽底に均一に分散している状態を初期条件とし て非定常解析を行い、流動状態および粒子の分散 が定常状態に達した擋汼開始から $8.0 〜 10.0 \mathrm{~s}$ の 間のデータについて統計的に取り扱った。なお、 本稿で対象とする槽底近傍および摚拌翼近傍で の粒子の挙動を上述の手法で解析するには、計算 格子の設定方法や時間ステップ幅、DEM 変数な どの決定が重要となる。摚找装置の設計時に重要 となる摚找所要動力、槽底での粒子の堆積状況、 擋汼羽根後方に形成される後流渦の生成状況な どについての実験結果との比較による詳細な検 討が必要となるが、紙面の都合上ここでは説明を 割愛する。

\section{3. 擋找槽の槽底からの固体粒子の浮遊挙動}

摚拌翼の設置高さが $h=H / 3$ の場合において、 槽内が定常状態に達した後の槽底近傍の水平方 向の時間平均流速 $V_{\mathrm{f}, \mathrm{r}-\theta}$ のベクトル図を Fig. 2 に、 粒子堆積領域を Fig. 3 に示す。Fig. 3 は、槽底近 傍に存在する粒子の位置を経時的に重ね合わせ たものである。摚拌羽根の回転により羽根から水 平方向に吐出された流動は、槽壁近傍で邪魔板の 前面に沿った下降流となり槽底中心に強く流れ 込む。Fig. 2 より、槽底近傍では邪魔板前面から 槽底中心方向一集束する流れが形成され、4枚の 邪魔板からの水平流はお互いにぶつかり合い、流 れのぶつかる位置では湾曲した十字状によどみ 領域が生じることがわかる。Figs. 2，3 より、槽 底近傍にある粒子は流れのよどみ領域に寄せ集 められ、その位置に堆積することがわかる。この ときの槽底近傍での鉛直方向の時間平均流速に 着目すると、Fig. 3 に示した水平流動のよどみ領 域に対応する位置に強い上昇流が生じることが 確認された(図は省略)。その上昇流に巻き込まれ て粒子は上方一浮遊し、擋汼羽根を介して槽全体 に分散することがわかった。

Fig. 4 に、擋拌羽根を槽底に近づけた $h=H / 10$ の場合における粒子の堆積位置の解析結果を示 す。槽底近傍では、槽底中心付近から槽壁方向人 放射状に向かう流れと、槽壁から槽底中心へ向か う弱い流れがぶつかりあい、その位置によどみ領 域が生じる(流速図は省略)。Fig. 4 より、粒子は
そのよどみ領域まで押し流されて堆積すること がわかる。よどみ領域に対応する位置に上昇流が 発生し、粒子はその流れに巻き込まれて浮遊する ことを確認した。邪魔板なし擋拌槽を用いた場合 についても同様に検討した。邪魔板なしの場合、 槽底中心付近では旋回流が発生し、軸の真下によ どみ領域が生じる。粒子はそのよどみ領域に堆積 し、よどみ領域の上方に上向きの上昇流が生じ、 その位置から粒子が浮遊することが確認された。

本研究で対象とした 3 つの装置条件において は、槽底近傍でのフローパターンは異なるものの、 (i) 槽底近傍に水平方向の流れがよどむ領域が形

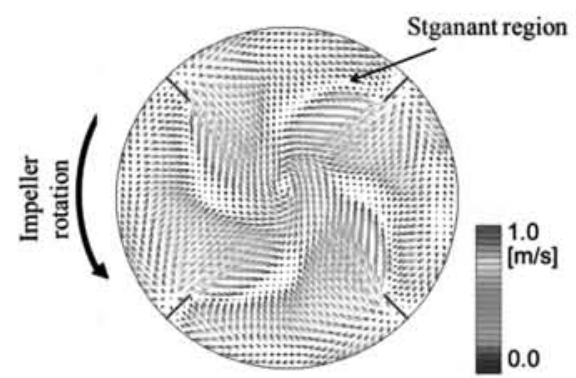

Fig. 2 Time averaged horizontal fluid velocity vectors, $V_{f, r-\theta}(h=H / 3)$.

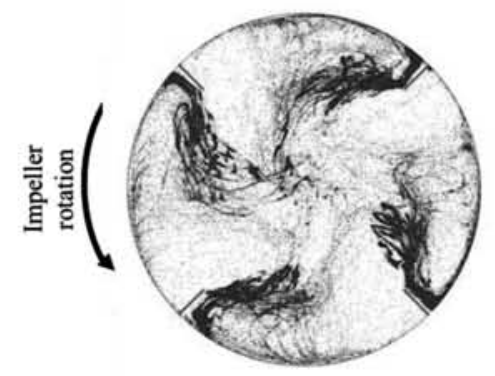

Fig. 3 Particle sedimentation pattern on the bottom ( $h$ $=H / 3)$.

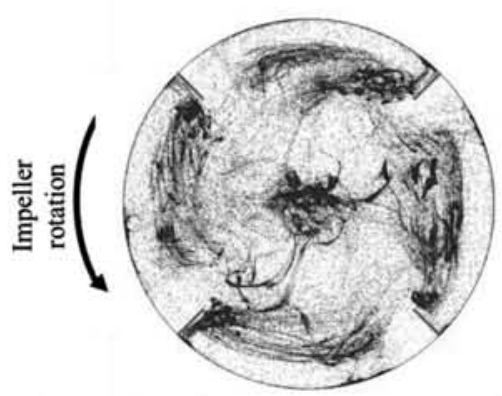

Fig. 4 Particle sedimentation pattern on the bottom $(h$ $=H / 10)$. 
成される、(ii) 流れのよどみ領域に粒子が寄せ集 められる、(iii) 流れのよどみ領域に上昇流が形成 される、(iv) 上昇流に巻き込まれて粒子が浮遊す る、の共通する 4 つの段階により粒子の浮遊現象 を説明できることがわかった。

\section{4. 摚找羽根への固体粒子の衝突現象}

\section{1 擋拌羽根周辺の流動状態}

粒子と摚拌羽根との衝突現象を詳細に定量化 するためには、摚找翼近傍の流動状態をできるだ け忠実に再現することが不可欠となる。Fig. 5 に、 6 枚パドル翼近傍の渦度の等值面を示す。摚拌翼 近傍の計算格子数を適切に設定した条件では、そ れぞれの擋汼羽根の回転方向背面から後方に伸 びる上下 1 対の等渦度面が形成される。これは Takashima ら[20]や van’t Riet ら[21]が実験的に観 察した Trailing vortex と呼ばれるらせん状の流れ であり、回転羽根近傍の流れに対する空間的な制 約が少ない摚找装置特有の現象である。障害物の 背面に形成されるいわゆるカルマン渦と同質で あるが、摚拌軸からの距離に応じて障害物である 擋拌羽根と流体の相対速度が変化し、摚拌翼の中 心から槽壁方向に大きな移流を伴いながら背面 渦は大きく発達する点で、カルマン渦と異なる特 徵をもつ。Trailing vortex は、固体粒子と摚汼羽 根の衝突現象や、摚拌翼近傍で液滴や気泡が分裂 する現象と密接に関連することが指摘されてお り、異相系の擋汼操作をコンピュー夕解析する際 には、忠実に再現されることが望まれる。

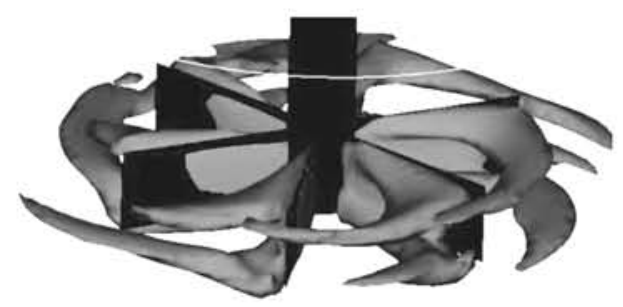

Fig. 5 Isosurface of vorticity formed behind blades of paddle impeller $\left(n=6.0 \mathrm{~s}^{-1}\right)$.

\section{2 擋拌羽根への固体粒子の衝突速度の分布}

擋拌羽根一の固体粒子の衝突現象は、晶析操作 における二次核発生現象と関連して、古くから実 験的な検討が試みられてきた[22-26]。これらの研 究の多くは、衝突頻度の測定、もしくは間接的な
手法による衝突エネルギーの推算にとどまって おり、固体粒子の衝突現象を整理するうえで重要 な衝突速度の定量化は不十分だといえる。

Fig. 6 に羽根前面での粒子衝突位置を示す。同 図より翼の種類や、羽根幅によらず、羽根の縁に 沿って速い衝突が起こることがわかる。Fig. 7 に $n=6 \mathrm{~s}^{-1}$ のときの各翼での羽根前面への法線方向 の衝突速度 $v_{\text {coll, }, \mathrm{f}, \mathrm{n}}$ の確率密度 $P\left(v_{\text {coll }, \mathrm{f}, \mathrm{n}}\right)$ を示す。同 図より、翼回転数が同じ場合、速い衝突速度の確 率密度はディスクタービン翼 $b=1 \mathrm{~cm}$ 、パドル翼 $b=1 \mathrm{~cm} 、 2 \mathrm{~cm} 、 3 \mathrm{~cm}$ の順に小さくなることがわ かる。Fig. 6 に示したように、羽根の縁に沿って 速い衝突が多く起こるため、羽根の面積に対する 縁の長さの割合が大きい翼ほど、速い衝突速度の 確率密度が大きくなったと考えられる。さらに、

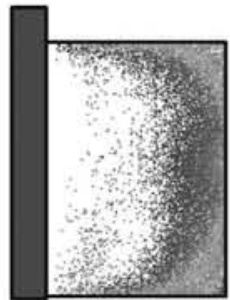

(a) Paddle (b=0.03 m)

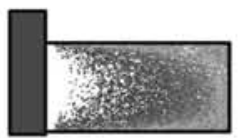

(c) Paddle $(b=0.01 \mathrm{~m})$

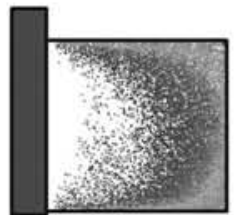

(b) Paddle $(b=0.02 \mathrm{~m})$

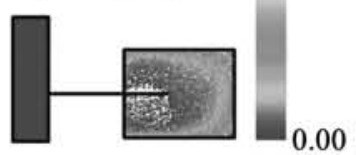

(d) Disc-Turbine ( $b=0.01 \mathrm{~m})$
Fig. 6 Distribution of particle collision points on the front face of impeller blade $\left(n=6 \mathrm{~s}^{-1}\right)$.

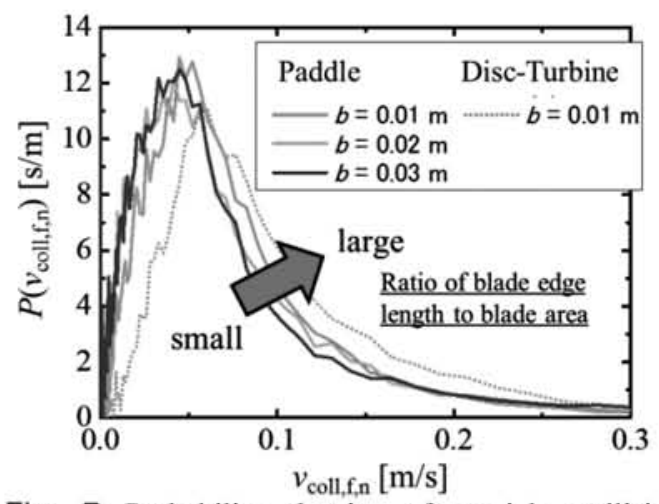

Fig. 7 Probability density of particle collision velocity with the front face $\left(n=6 \mathrm{~s}^{-1}\right)$. 
Fig. 6(d)より、ディスクタービン翼では軸から離 れた位置に羽根があるため、パドル翼で見られた 軸近くでの遅い衝突が起こらないことが、速い衝 突速度の確率密度を大きくする原因になったと 考えられる。

Fig. 8 に、摚汼羽根前面、および背面における 固体粒子の衝突位置、衝突速度の分布を示す。同 図より、羽根前面においては、羽根の縁に沿って 粒子の衝突は多く発生し、羽根の先端に向かうほ ど、衝突速度が大きくなることがわかる。一方、 羽根背面においては、粒子の衝突は羽根縁から離 れた羽根面の中心付近に集中し、前面とは異なる 分布を示す。

Fig. 9 に摚汼羽根近傍での粒子の軌跡の一例を 示す。摚找翼の回転により羽根の前面一向から粒 子は、羽根の表面近傍で羽根の先端、もしくは羽 根の上下の縁の方向へ向きを変え、羽根後方へと 通過する。羽根の縁から背面側人まわり込むさい に、一部の粒子は羽根の縁に衝突する。羽根の背 面へまわりこんだ粒子は、Trailing vortex に巻き もまれ、羽根背面の中央付近に集中して衝突する ことがわかる。

本稿では紹介できなかったが、著者らのグルー プでは、粒子衝突に対する粒子の特性(粒子径や 比重)の影響、羽根の設置高さの影響などについ ても現象の整理を進めており、また粒子衝突速度 を実験的に直接測定する計測システムも構築し ており、同現象のモデル化を進めていきたい。

\section{5. むすびに}

固液摚拌操作は、人類が火を使い惹炊きを始め た頃から行われる最古の単位操作の一つといえ るが、その混相流的な観点からの理解は意外と進 んでいない。混ぜる操作は身近なものであるため、 ある程度の混合は比較的容易に達成することが できる。一方で、伝統的な酒造りにおいては、「櫂 でつぶすな、羡で溶かせ」と言われている。まさ に摚拌羽根への衝突を抑制したうえで、固体粒子 からの物質移動速度を最大化させる操作が重要 視されており、工業プロセスの最適化には摚拌技 術の理解が欠かせない。

本稿では、固液摚拌操作を中心に紹介したが、 化学プロセスにおける摚拌操作は、必ず混合や化 学反応の対象が存在し、単相系として取り扱うこ とは少ない。液液系、気液系、固気液系に加えて、

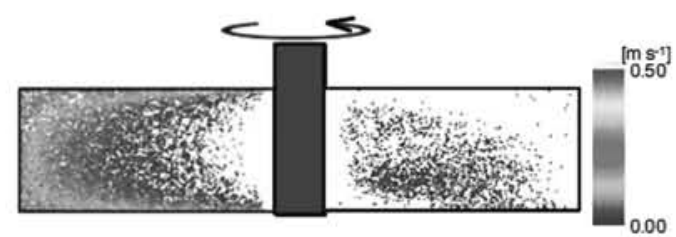

Fig. 8 Comparison of particle collision points between the front and back face of impeller blade $\left(n=6 \mathrm{~s}^{-1}\right)$.

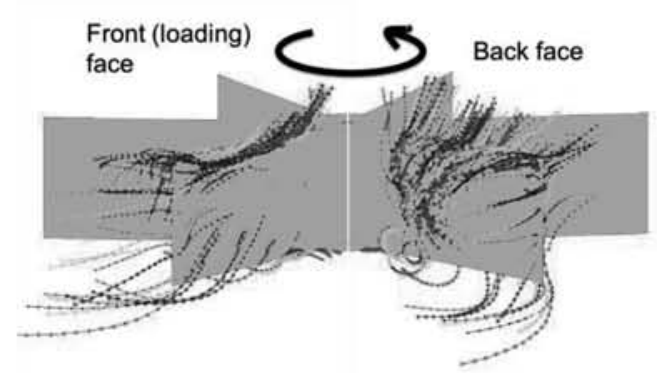

Fig. 9 Particle trajectories around impeller blade $(n=$ $\left.6 \mathrm{~s}^{-1}\right)$.

層流から乱流までを対象としており混相流現象 の宝庫といえる。CFD 技術の発達により、摚拌槽 内の単相系の流動状態はある程度の確かさで解 析できるようになってきたが、プロセスの目的に 応じた輸送現象的・反応工学的な情報(物質移動 係数や連続相と分散相の界面積、反応速度など) を抽出するための現象モデルの開発や、液相現象 における大きなシュミット数への対応、解析結果 の検証に不可欠な実験データの取得は不十分で ある。近年では、動物細胞培養やタンパク質結晶 の生産、連続相と分散相の片方、または両方が高 粘度液となる混相流など従来の摚找技術だけで は十分に対応できない事例も増えてきている。本 稿を読まれた方に、摚拌技術研究について興味を 持っていただければ幸いである。

\section{謝 辞}

本稿で紹介した研究は、横浜国立大学の（元） 学生 中村直貴君、佐藤祐自君、中西良輔君、枡 井康広君、佐々木拓二君、加藤勇人君、飯島広成 君、戸村俊君の協力のもとに行われた。また、ソ ルト・サイエンス研究財団の研究助成 (Nos. 0617 and 1419)、ならびに文部科学省科学研究費補助金 （Nos. 19760112, 23760147 and 25420108）の援助 
を受けて行われたものである. 記して、謝意を表 す。

\section{Nomenclature}

$b \quad$ : width of impeller blade

$B$ : width of baffle plate

$d$ : impeller diameter

[m]

[m]

[m]

$h$ : impeller equipped height

[m]

$H \quad$ : liquid level

$n \quad$ : impeller rotational speed

$n_{J S}:$ minimum rotational speed of impeller at which particles just become completely suspended

$[1 / \mathrm{s}]$

$P \quad$ : probability density of collision velocity $[\mathrm{s} / \mathrm{m}]$

$T$ : vessel diameter

[m]

$V_{\text {coll }, f, n}:$ particle collision velocity normal to front face of blade

$[\mathrm{m} / \mathrm{s}]$

$V_{f, r-\theta} \quad$ : fluid velocity in $\mathrm{r}-\theta$ plane

$[\mathrm{m} / \mathrm{s}]$

\section{Subscripts}

$t \quad$ : fluid phase

$n \quad$ : normal component to blade face

$r, \theta, z:$ axes in cylindrical coordinates system

\section{参考文献}

[1] Zwietering, T.N., Suspending of solid particles in liquid by agitators, Chem. Eng. Sci., Vol.8(3-4), 244-253 (1958).

[2] Nagata, S., Yokoyama, T. and Naka, H., Studies on the Solid-Liquid agitation - (III) Empirical Formula to Estimate the Critical Agitator Speed -, Chemical engineering, Vol.17(4), 144-151 (1953).

[3] Misumi, R., Kato, S., Ibe, S., Nishi, K. and Kaminoyama, M., Highly Efficient Evaporative Crystallization of a High Suspension Density Sodium Chloride Slurry in a Draft-Tube Stirred Vessel in Continuous Operation, J. Chem. Eng. Jpn., Vol.44(4), 240-246 (2011).

[4] Wu, J., Ngyuen, B., Graham, L., Zhu, Y., Kilpatrick, T. and Davis, J., Minimizing impeller slurry wear through multilayer paint modelling, Can. J. Chem. Eng., Vol.83(5), 835-842 (2005).

[5] Misumi, R., Kato, H., Iijima, H., Nishi, K. and Kaminoyama, M., Relation between Particle Collisions and Paint Erosion on Impeller Blades, Proc. of International Symposium on Mixing in Industrial Processes 8 (ISMIP8), 62-63 (2014).

[6] Hiraoka, S., Yamada, I., Aragaki, T., Nishiki, H., Sato, A. and Takagi, T., Numerical Analysis of Three Dimensional Velocity Profile of Highly Viscous Newtonian Fluid in an Agitated Vessel with Paddle Impeller, J. Chem. Eng. Jpn., Vol.21(1), 79-86 (1988).
[7] Kaminoyama, M., Saito, F. and Kamiwano, M., Numerical Analysis of Three Dimensional Flow Behaviour of Pseudoplastic Liquid in a Stirred Vessel with Turbine Impellers, KAGAKU KOGAKU RONBUNSHU, Vol.14(6), 786-793 (1988).

[8] Kaminoyama, M., Saito, F. and Kamiwano, M., Flow Analogy of Pseudoplastic Liquid in Geometrically Similar Stirred Vessels Based on Numerical Analysis, J. Chem. Eng. Jpn., Vol.23(2), 214-221 (1990).

[9] Takeda, H., Narasaki, K., Kitajima, H., Sudoh, S., Onofusa, M. and Iguchi, S., Numerical simulation of mixing flows in agitated vessels with impellers and baffles, Computers \& Fluids, Vol.22(2-3), 223-228 (1993).

[10] Marshall, E.M. and Bakker, A., Handbook of Industrial Mixing - Science and Practice -, 257-343, John Wiley \& Sons, Inc., New Jersey (2004).

[11] Bakker, A., Laroche, R.D., Wang, M.H. and Calabrese, R.V., Sliding Mesh Simulation of Laminar Flow in Stirred Reactors, Chem. Eng. Res. Des., Vol.75(1), $42-44$ (1997).

[12] Derksen, J.J., Numerical simulation of solids suspension in a stirred tank, AlChE J., Vol.49(11), 2700-2714 (2003).

[13] Rielly, C.D. and Marquis, A.J., A particle's eye view of crystallizer fluid mechanics, Chem. Eng. Sci., Vol.56(7), 2475-2493 (2001).

[14] Misumi, R., Nakamura, N., Nishi, K. and Kaminoyama, M., Effects of Instantaneous Slip Velocity and Solute Distribution on the Dissolution Process of Crystal Particles in a Stirred Vessel, J. Chem. Eng. Jpn., Vol.37(12), 1452-1460 (2004).

[15] Misumi, R., Sasaki, T., Kato, H., Nishi, K. and Kaminoyama, M., Relation between particle rising behavior and liquid flow around the bottom of a stirred vessel, Proc. of 14th European Conference on Mixing, 299-304 (2012).

[16] Misumi, R., Nakanishi, R., Masui, Y., Nishi, K. and Kaminoyama, M., Lagrangian Numerical Simulation of Crystal Particle Impact in a Stirred Vessel, Proc. of 2nd Asian Conference on Mixing 2008, 269-275 (2008).

[17] Misumi, R., Kato, H., Iijima, H., Nishi, K. and Kaminoyama, M., Quantification of Particle Collision on Impeller Blades in a Stirred Vessel, Proc. of 4th Asian Conference on Mixing, 201-204 (2013).

[18] Cundall, P.A. and Strack, O.D.L., Discrete Numerical-Model for Granular Assemblies, Geotechnique, Vol.29(1), 47-65 (1979).

[19] Tsuji, Y., Kawaguchi, T. and Tanaka, T., Discrete particle simulation of two-dimensional fluidized bed, Powder Technol., Vol.77(1), 79-87 (1993). 
[20] Takashima, I. and Mochizuki, M., Tomographic Observations of the Flow around Agitator Impeller, J. Chem. Eng. Jpn., Vol.4(1), 66-72 (1971).

[21] van't Riet, K. and Smith, J.M., The behaviour of gas-liquid mixtures near Rushton turbine blades, Chem. Eng. Sci., Vol.28(4), 1031-1037 (1973).

[22] Nienow, A.W., The Effect of Agitation and Scale-up on Crystal Growth and on Secondary Nucleation, Trans. Instn. Chem. Engrs., Vol.54, 205-207 (1976).

[23] Takahashi, K., Gidoh, Y., Yokota, T. and Nomura, T., Particle-Impeller Impact in an Agitated Vessel Equipped with a Rushton Turbine, J. Chem. Eng. Jpn., Vol.25(1), 73-77 (1992).
[24] Kee, K.C. and Rielly, C.D., Measurement of particle impact frequencies and velocities on impeller blades in a mixing tank, Chemical Engineering Research \& Design, Vol.82(A9), 1237-1249 (2004).

[25] Isaji, M., Ookawara, S. and Ogawa, K., Correlation Equation of Particle Collision Frequency with Impeller in a Stirred Tank, KAGAKU KOGAKU RONBUNSHU, Vol.32(4), 315-326 (2006).

[26] Misumi, R., Crystal particle collision with impeller blade and particle attrition in a stirred type crystallizer, Recent Advances in Chemical Engineering 64, Sankeisha (2015) (in press). 